\title{
High prevalence and incidence of sexually transmitted infections among women living in Kwazulu-Natal, South Africa
}

\author{
Sarita Naidoo ${ }^{1 *}$, Handan Wand ${ }^{2}$, Nathlee Samantha Abbai ${ }^{1}$ and Gita Ramjee ${ }^{1,3}$
}

\begin{abstract}
Background and objectives: Sexually transmitted infections (STIS) contribute largely to the burden of health in South Africa and are recognized as major contributors to the human immunodeficiency virus (HIV) epidemic. Young women are particularly vulnerable to STIs. The purpose of this secondary analysis was to examine the risk factors associated with prevalent and incident STIs among women who had participated in three clinical trials.

Methods: A total of 5,748 women were screened and 2293 sexually active, HIV negative, non-pregnant women were enrolled in three clinical trials in Kwazulu-Natal, South Africa. The prevalence of individual STIs Chlamydia trachomatis (CT), Neisseria gonorrhea (NG), syphilis, and Trichomonas vaginalis (TV) was assessed at screening; and incident infections were evaluated over a 24 month period.

Results: Overall, the combined study population of all three trials had a median age of 28 years (inter-quartile range (IQR):22-37), and a median duration of follow-up of 12 months. Prevalence of STIs (CT, NG, TV, or syphilis) was $13 \%$ at screening. The STI incidence was estimated to be 20/100 women years. Younger women $(<25$ years, $p<0.001)$, women who were unmarried $(p<0.001)$ and non-cohabiting women $(p<0.001)$ were shown to be at highest risk for incident STIs.
\end{abstract}

Conclusions: These results confirm the extremely high prevalence and incidence of STIs among women living in rural and urban communities of KwaZulu-Natal, South Africa, where the HIV epidemic is also particularly severe. These findings strongly suggest an urgent need to allocate resources for STI and HIV prevention that mainly target younger women.

Trial registration: Clinical Trials.gov, NCT00121459.

Keywords: Sexually transmitted infections, HIV, Kwa-Zulu Natal, Women, Prevalence, Incidence, Risk factors

\section{Introduction}

South Africa (SA) is at the epicenter of the human immunodeficiency virus (HIV) epidemic; and other sexually transmitted infections (STIs) continue to be endemic [1-3]. STIs have been associated with pelvic inflammatory disease, adverse pregnancy outcomes, cervical cancer, infertility, and multiple reproductive tract sequelae [4]. Furthermore, the evidence that STIs facilitate HIV acquisition and transmission [5,6] enhances the seriousness of the problem.

\footnotetext{
* Correspondence: sarita.naidoo@mrc.ac.za

${ }^{1}$ HIV Prevention Research Unit, South African Medical Research Council, Durban, South Africa

Full list of author information is available at the end of the article
}

KwaZulu-Natal (KZN), the most densely populated province in SA, has been markedly affected by both the HIV and STI epidemic [7,1]; with a disproportionate burden of STIs and HIV among women. Several studies conducted within various populations of women in KZN have shown high prevalence of HIV coupled with STIs [8-11]. Control of STIs therefore remains extremely important in these high risk populations. Availability of data on the epidemiology of STIs and associated risk factors in these populations is thus essential for the development of successful targeted interventions in this region.

This study presents combined data from a large cohort of women, from urban and rural areas of $\mathrm{KZN}$, who 
participated in three clinical trials; to determine the prevalence and incidence of STIs [(Chlamydia trachomatis (CT), Neisseria gonorrhea (NG), syphilis, and Trichomonas vaginalis (TV)] and the associated risk factors. This data provides an opportunity to gain further insights into the overall STI prevalence and incidence in this region; and will inform the design of future HIV/STI prevention strategies by identifying and defining populations most at risk.

\section{Methods}

\section{Study population}

This analysis includes women who participated in three multi-centre trials at sites in KZN: Methods for Improving Reproductive Health in Africa (MIRA) trial [12], conducted in rural Umkomaas and Botha's Hill; Microbicides Development Programme (MDP) Feasibility study in preparation for Phase III Microbicide Trials [13], in semi-rural Tongaat and Verulam; and HIV Prevention Trials Network (HPTN) Site Preparedness study (HPTN 055) for future implementation of Phase 2/IIb/III HIV Prevention Studies [14], in an urban area in Durban and in a rural district of Hlabisa. Study populations were described elsewhere in detail [12-14].

\section{Study procedures}

Study procedures were described in detail elsewhere [12-14]. Main inclusion criteria were similar in all three studies, and briefly included being sexually active; HIV negative at screening; not pregnant, willing to provide written consent, and follow study procedures. Information on demographics and sexual behaviors were collected. Participants received risk reduction counseling and condoms; and treatment was provided for curable, symptomatic or laboratory-diagnosed STIs. Women diagnosed as HIV-positive were referred to local health care facilities for further care and support. Male partners were encouraged to access the trial sites for counseling, HIV testing and STI treatment. Additionally, women diagnosed with STIs were given referrals for their partners to access treatment at local clinics. Study protocols and informed consent forms were approved by the local ethics committee and various Institutional Review Boards.

\section{Laboratory procedures}

STI and HIV testing was described previously for each study $[12,15,16]$. Briefly, in the MIRA trial, [16] CT, GC and TV were detected by PCR (Roche Pharmaceuticals, Branchburg, NJ, USA) and syphilis by rapid plasma reagin (RPR) and Treponema pallidum haemagglutinin (TPHA) (Randox Laboratories, Crumlin, UK). In HPTN 055 [15], CT and GC were detected using the BDProbe Tec ET assay (Becton Dickinson, MD), TV by wet mount microscopy and syphilis by RPR and confirmatory TPHA.
In MDP Feasibility [16], CT and GC were detected using PCR (COBAS Amplicor, Roche Molecular Diagnostics, Pleasanton, CA, USA), TV by wet mount microscopy and syphilis by RPR and confirmatory TPHA (Omega Diagnostics, Alva, UK).

\section{Statistical analysis}

Differences in proportions were tested using the chisquare test. The Student's t test was used to compare averages. Univariate and multivariate logistic regression analyses were conducted to identify variables predictive of any STI (CT, NG, TV or Syphilis) infection at screening. Only variables determined to be consistent across the studies were included.

STI incidence was determined as the first positive test after a negative test at enrollment. Associations between various factors and STI incidence were described using Kaplan-Meier survival plots and log-rank tests. Risk factors for STI incidence were assessed using Cox proportional hazard regression models. Multivariate models considered all variables statistically significant $(\mathrm{p}<0.05)$ in initial analyses and used forward stepwise methods. Statistical analysis was performed using STATA Release 8.2 (Stata Statistical Software: Stata Corporation, College Station, Texas, USA).

\section{Results}

Of the 5,748 women screened, 3492 were from the MIRA trial, 1221 from MDP Feasibility; and 1035 from HPTN055. Overall, the women had a median age of 28 years (interquartile range (IQR):22-37), and a median duration of follow-up of 12 months (data not shown). Majority were from rural areas (91\%); unmarried (85\%); and not living with regular sexual partners (non-cohabiting) (68\%). Over half (53\%) reported less than high school education. HIV and STI (diagnosed with at least one STI: CT, NG, TV or syphilis) prevalence at baseline was 42\% (2407/5748) and 13\% (738/5748), respectively.

\section{Risk factors for STIs at screening}

Women with prevalent STIs $(\geq 1)$ were younger $(<25$ years $)$ $(\mathrm{p}<0.001)$; reported less than high school education $(\mathrm{p}<0.0001)$, were unmarried $(\mathrm{p}<0.0001)$; and noncohabiting $(\mathrm{p}<0.0001)$ (Table 1$)$. Table 2 shows that women who were HIV positive, $<25$ years of age; unmarried; non- cohabiting; and who reported less than high school education were significantly associated with increased risk of having a prevalent STI (Odds Ratios (OR):1.50, 95\% Confidence Intervals (CI):1.271.76; OR:1.36, 95\% CI:1.11-1.68; OR:1.60, 95\% CI:1.142.24; OR:1.27,95\% CI:1.03-1.60; and OR:1.75, 95\% CI:1.49-2.06 respectively). 
Table 1 Demographic variables by $\mathrm{STI}^{\dagger}$ status at screening

\begin{tabular}{|c|c|c|c|c|}
\hline Variables & $\begin{array}{l}\text { Overall } \\
\mathrm{N}=5,748(\%)\end{array}$ & $\begin{array}{l}\mathrm{STI}+ \\
\mathrm{N}=728(\%)\end{array}$ & $\begin{array}{l}\text { STI- } \\
\mathrm{N}=5,020(\%)\end{array}$ & $p$-value \\
\hline HIV prevalence at screening & $2,407(42)$ & $375(52)$ & $2,032(40)$ & $<0.001$ \\
\hline District & & & & 0.524 \\
\hline Rural $^{\ddagger}$ & $5216(91)$ & $656(90)$ & $4560(91)$ & \\
\hline Urban $^{\top}$ & $532(9)$ & $72(10)$ & $460(9)$ & \\
\hline Age, mean (SD) & $28.6(8)$ & $26(7)$ & $29(8)$ & \\
\hline \multicolumn{5}{|l|}{ Age groups (years) } \\
\hline$\leq 24$ & $2,223(39)$ & $367(50)$ & $1856(37)$ & $<0.001$ \\
\hline $25-34$ & $2,224(39)$ & $255(35)$ & 1969 (39) & \\
\hline $35+$ & $1,305(22)$ & $106(15)$ & $1199(24)$ & \\
\hline \multicolumn{5}{|l|}{ Education } \\
\hline Less than high school & $3069(53)$ & $467(61)$ & $2602(52)$ & $<0.0001$ \\
\hline \multicolumn{5}{|l|}{ Marital status } \\
\hline Not married & $4,912(85)$ & $677(93)$ & $4235(84)$ & $<0.0001$ \\
\hline \multicolumn{5}{|l|}{ Co-habitation status } \\
\hline Non-cohabiting & $3,929(68)$ & $566(78)$ & $3363(70)$ & $<0.0001$ \\
\hline
\end{tabular}

${ }^{\dagger}$ Diagnosis of chlamydia, gonorrhea, trichomonas or syphilis.

${ }^{\ddagger}$ Hlabisa, Umkomaas, Botha's Hill, Tongaat and Verulam.

${ }^{\top}$ Durban.

\section{Incidence of STIs}

Crude STI incidence amongst the 2293 enrolled women was 680 (20/100 women-years). Kaplan-Meier survival curves of infection stratified by age, marital, and cohabitation status are shown in Figure 1a-c. The highest incidence rate was observed for women $<25$ years old $(26 / 100$ women-years, $\mathrm{p}<0.001)$, followed by moderately high incidence rates for unmarried and non-cohabiting women (22/100 women-years, $\mathrm{p}<0.001$ and 21/100 women-years, $\mathrm{p}<0.001$; respectively).

Table 3 shows that baseline STI infection, being $<25$ years of age; unmarried; and non-use of contraception were significantly associated with increased risk of acquiring incident STIs (OR:1.52, 95\% CI:1.22-1.88; OR:1.40, 95\% CI:1.14-1.74; OR:1.54, 95\% CI:1.22-1.94 and OR:1.40, 95\% CI:1.19-1.64, respectively). No significant associations with

Table 2 Risk factors for being diagnosed with STI at screening: results from univariate and multivariate logistic regression models

\begin{tabular}{|c|c|c|c|c|}
\hline Variable & $\begin{array}{l}\text { Univariate analysis } \\
\text { OR }(95 \% \mathrm{CI})\end{array}$ & p-value & $\begin{array}{l}\text { Multivariate analysis } \\
\text { OR }(95 \% \mathrm{CI})\end{array}$ & p-value \\
\hline \multicolumn{5}{|l|}{ HIV infection status } \\
\hline HIV negative & 1 & & 1 & \\
\hline HIV positive & $1.56(1.34-1.83)$ & $<0.0001$ & $1.50(1.27-1.76)$ & $<0.0001$ \\
\hline \multicolumn{5}{|l|}{ Age (years) } \\
\hline$<25$ & $1.60(1.33-1.92)$ & 0.000 & $1.36(1.11-1.68)$ & 0.003 \\
\hline $25-34$ & $1.17(0.95-1.43)$ & 0.137 & $1.08(0.87-1.34)$ & 0.480 \\
\hline $35+$ & 1 & - & 1 & - \\
\hline \multicolumn{5}{|l|}{ Education } \\
\hline Less than high school & $1.67(1.42-1.96)$ & $<0.00001$ & $1.75(1.49-2.06)$ & $<0.0001$ \\
\hline \multicolumn{5}{|l|}{ Marital status } \\
\hline Not married & $2.47(1.84-3.32)$ & $<0.0001$ & $1.60(1.14-2.24)$ & 0.006 \\
\hline \multicolumn{5}{|l|}{ Co-habitation status } \\
\hline Non-cohabiting & $1.73(1.43-2.07)$ & $<0.0001$ & $1.27(1.03-1.60)$ & 0.024 \\
\hline
\end{tabular}

$\mathrm{Cl}$, confidence interval; OR, odds ratio. 

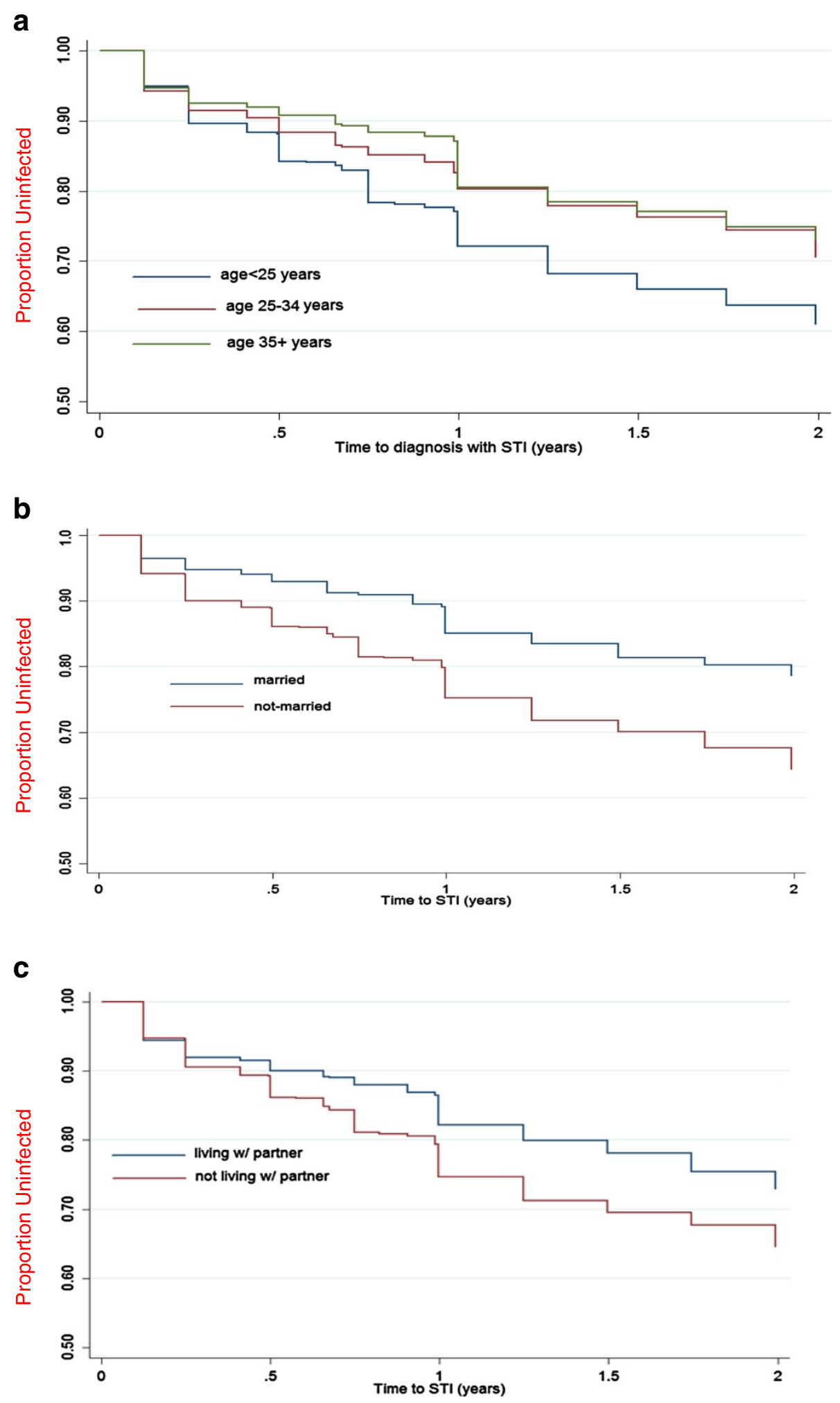

Figure 1 The Kaplan-Meier survival curves of STI incidence stratified by age (a), marital status (b) and cohabitation status (c). 
Table 3 Risk factors for incidence of STI during follow up: results from cox regression models

\begin{tabular}{|c|c|c|c|c|}
\hline Variable & $\begin{array}{l}\text { Univariate analysis } \\
\text { HR }(95 \% \mathrm{Cl})\end{array}$ & p-value & $\begin{array}{l}\text { Multivariate analysis } \\
\text { HR }(95 \% \mathrm{Cl})\end{array}$ & p-value \\
\hline Any STI at baseline & $1.61(1.30-2.00)$ & - & $1.52(1.22-1.88)$ & 0.000 \\
\hline \multicolumn{5}{|l|}{ Age } \\
\hline$\leq 25$ & $1.64(1.36-2.00)$ & $<0.001$ & $1.40(1.14-1.74)$ & 0.001 \\
\hline 25-34 & $1.19(0.97-1.46)$ & 0.100 & $1.10(0.89-1.37)$ & 0.370 \\
\hline $35+$ & 1 & - & & \\
\hline \multicolumn{5}{|l|}{ District } \\
\hline Rural & $0.93(0.69-1.25)$ & 0.628 & - & \\
\hline Urban & 1 & - & & \\
\hline \multicolumn{5}{|l|}{ Employed/income } \\
\hline No & $1.35(1.10-1.66)$ & 0.0038 & - & \\
\hline Yes & 1 & - & & \\
\hline \multicolumn{5}{|l|}{ Level of education } \\
\hline High school or more & 1 & - & & \\
\hline Less than high school & $1.25(1.06-1.46)$ & 0.006 & - & \\
\hline \multicolumn{5}{|l|}{ Contraceptive use } \\
\hline At least one form of contraceptive ${ }^{1}$ & 1 & - & & \\
\hline None & $1.33(1.13-1.55)$ & $<0.001$ & $1.40(1.19-1.64)$ & 0.000 \\
\hline \multicolumn{5}{|l|}{ Marital status } \\
\hline Married & 1 & - & & \\
\hline Not married & $1.84(1.49-2.27)$ & $<0.0001$ & $1.54(1.22-1.94)$ & 0.000 \\
\hline \multicolumn{5}{|l|}{ Cohabitation status } \\
\hline Yes & 1 & - & & \\
\hline No & $1.43(1.21-1.68)$ & $<0.0001$ & - & \\
\hline \multicolumn{5}{|l|}{ Condom used during last sexual act } \\
\hline No & $1.00(0.86-1.16)$ & 0.98 & - & \\
\hline Yes & 1 & - & & \\
\hline
\end{tabular}

$\mathrm{Cl}$, confidence interval; HR Hazard ratio.

${ }^{1}$ including condom, injectables, pills, traditional methods.

incident STIs were observed for geographical area, employment status, condom use and education level.

\section{Discussion}

Our analysis confirms that STI prevalence and incidence is extremely high in women living in KZN. The prevalence of STIs was $13 \%$ while the incidence rate was 20/ 100 women-years. Similar STI incidence was reported in other studies conducted in SA [15,17-19]. Incidence of STIs in this cohort was unacceptably high despite provision of risk reduction counseling, condoms, treatment for curable STIs; and partner treatment or referral.

In this study, women who were < 25 years; unmarried; and non-cohabiting were identified as being at most risk for STI acquisition. Recent evidence from a PrEP trial, VOICE, conducted in SA, Zimbabwe and Uganda, showed the same risk factors associated with increased risk of HIV acquisition [20]. Similarly, Feldblum and colleagues [19] observed that younger age was associated with incident HIV and STIs. Another study also showed that younger women were at higher risk of acquiring new STIs [18]. Studies in Tanzania [21], Kenya [22] and Brazil [23] reported that being unmarried was associated with STI acquisition.

Predictably, having an STI at baseline also placed women at increased risk of acquiring an STI during follow up, and at substantial risk of HIV acquisition. HIV infection at screening was associated with a significantly higher prevalence among women diagnosed with at least one STI compared to those who had no STI; providing further evidence for the relationship between HIV and STIs. Mlisana and colleagues [17] reported a similar finding. It was also previously suggested that HIV prevention efforts in SA may be enhanced by screening STI patients for acute HIV infection [6].

This study defined populations who are most at risk of STI acquisition and broadly showed the common risk 
factors associated with STI prevalence and incidence suggesting the need for effective behavioural or biomedical interventions. This data will aide in the design of future interventions in these populations; and contributes to the STI surveillance data for women in this region.

Our study has several limitations. These results may not be representative of the wider population as these women were recruited from selected populations. However this large data set, together with the numerous STIs detected, provides valuable information on the STI epidemic in this region. Another limitation is the slight variations in testing methods used for STI diagnosis in the different trials, where some methods may have been more sensitive than others. Additionally, the risk factor analyses were restricted to socio-demographic and behavioral variables that were assessed consistently across all three studies, possibly resulting in reducing the power of the analyses to detect significant associations. Finally, although all STIs were treated, there was no information on partner infection status or resistant infections during follow up.

\section{Conclusions}

Due to the high incidence of STIs observed in this population, targeted interventions aimed at young women and their partners, are urgently needed. Control and treatment of STIs still remains an important public health priority for HIV prevention and should include a combination of prevention efforts such as extensive health education, condom promotion, male circumcision, and HIV and STI testing in all patient-provider encounters.

\section{Competing interests}

The authors declare that they have no competing interests.

\section{Authors' contribution}

GR and HW developed the concept. HW conducted the statistical analysis. SN wrote the manuscript with input from GR, HW and NSA. All authors read and approved the final manuscript.

\section{Authors' information}

Handan Wand, Nathlee S Abbai, Gita Ramjee Co-authors.

\section{Acknowledgements}

We would like to thank all the women who participated in these studies; and the MIRA, HPTN 055 and MDP Feasibility study teams at the South African Medical Research Council, HIV Prevention Research Unit (Durban).

\section{Funding}

We gratefully acknowledge the financial support of the UK Medical Research Council, the UK Department for International Development (MDP Feasibility study: Grant number G0100137), the Bill and Melinda Gates Foundation (MIRA: Grant number 21082) and the Division of AIDS of the National Institutes of Health, USA (HPTN 055: Grant number U01 Al048008).

\section{Author details}

${ }^{1}$ HIV Prevention Research Unit, South African Medical Research Council, Durban, South Africa. ${ }^{2}$ National Center for HIV Epidemiology and Clinical Research, Sydney, Australia. ${ }^{3}$ Department of Epidemiology and Population Health, London School of Hygiene \& Tropical Medicine, London, UK.
Received: 21 March 2014 Accepted: 9 September 2014

Published: 15 September 2014

\section{References}

1. Johnson LF, Coetzee DJ, Dorrington RE: Sentinel surveillance of sexually transmitted infections in South Africa: a review. Sex Transm Infect 2005, 81:287-293. doi:10.1136/sti.2004.013904.

2. Johnson LF, Dorrington RE, Bradshaw D, Coetzee DJ: The effect of syndromic management interventions on the prevalence of sexually transmitted infections in South Africa. Sex Reprod Healthc 2011, 2:13-20.

3. Johnson L, Bradshaw D, Dorrington R, South African Comparative Risk Assessment Collaborating Group: The burden of disease attributable to sexually transmitted infections in South Africa in 2000. S Afr Med J 2007 97:658-662.

4. Aral SO, Over M, Manhart L, Holmes KK: Disease Control Priorities in Developing Countries. In Sexually Transmitted Infections. 2nd edition. Edited by Jamison DT, Breman JG, Measham AR, Alleyne G, Claeson M, Evans DB, Jha P, Mills A, Musgrove P. Washington (DC): World Bank; 2006.

5. Cohen MS: Classical sexually transmitted diseases drive the spread of HIV-1: back to the future. J Infect Dis 2012, 206(1):1-2.

6. Lewis DA: Detection and management of acute HIV infections in patients with sexually transmitted infections: a window of opportunity for HIV prevention within South Africa? South Afr J Epidemiol Infect 2012, 27(4):149-155.

7. Nel A, Mabude Z, Smit J, Kotze P, Arbuckle D, Wu J, van Niekerk N, van de Wijgert J: HIV incidence remains high in KwaZulu-Natal, South Africa: evidence from three districts. Plos One 2012, 7(4):e35278. doi:10.1371/ journal.pone.0035278.

8. Ramjee G, Williams B, Gouws E, van Dyck E, De Deken B, Abdool Karim S: The impact of incident and prevalent herpes simplex virus- 2 infection on the incidence of HIV-1 infection among commercial sex workers in South Africa. J Acquir Immune Defic Syndr 2005, 39:333-339.

9. Frolich JA, Abdool Karim O, Mashego MM, Sturm AW, Abdool Karim SS: Opportunities for treating sexually transmitted infections and reducing HIV risk in rural South Africa. J Adv Nurs 2007, 60(4):377-383. doi:10.1111/ j.1365-2648.2007.04405.x

10. Wilkinson D, Connolly AM, Harrison A, Lurie M, Abdool Karim SS: Sexually transmitted disease syndromes in rural South Africa: results from health facility surveillance. Sex Trans Dis 1998, 25(1):20-23.

11. Hoque ME: Reported risky sexual practices amongst female undergraduate students in Kwazulu-Natal, South Africa. Afr J Prm Health Care Fam Med 2011, 3(1):Art. \#281,6. http://dx.doi.org/10.4102/phcfm. v3i1.281

12. Padian NS, van der Straten A, Ramjee G, Chipato T, de Bruyn G, Blanchard K, Shiboski S, Montgomery ET, Fancher $\mathrm{H}$, Cheng $\mathrm{H}$, Rosenblum $\mathrm{M}$, van der Laan M, Jewell N, McIntyre J, the MIRA team: Diaphragm and lubricant gel for prevention of HIV acquisition in southern African women: a randomized controlled trial. Lancet 2007, 370:251-261.

13. Nunn A, McCormack S, Crook AM, Pool R, Rutterford C, Hayes R: Microbicides development programme: design of a phase III trial to measure the efficacy of the vaginal microbicide PRO 2000/5 for HIV prevention. Trials 2009, 10:99.

14. Ramjee G, Kapiga S, Weiss S, Peterson L, Leburg C, Kelly C, Masse B, the HPTN 055 Study Team: The value of site preparedness studies for future implementation of phase 2/Ib/III HIV prevention trials. Experience from the HPTN 055 Study. J Acquir Immune Defic Syndr 2008, 47(1):93-100.

15. Kapiga S, Kelly C, Weiss S, Daley T, Peterson L, Leburg C, Ramjee G: Risk factors for incidence of sexually transmitted infections among women in South Africa, Tanzania, and Zambia: Results from HPTN 055 Study. Sex Transm Dis 2009, 36(4):199-206.

16. Ramjee G, Wand H, Whitaker C, McCormack S, Nunn A, Kelly C, Padian N HIV incidence among non-pregnant women living in selected rural, semi-rural and urban areas in Kwazulu-Natal. AIDS Behav 2012, 16:2062-2071. doi:10.1007/s10461-011-0043-7.

17. Mlisana K, Naicker N, Werner L, Roberts L, van Loggerenberg F, Baxter C, Passmore JS, Grobler AC, Sturm AW, Williamson C, Ronacher K, Walzl G, Abdool Karim SS: Symptomatic vaginal discharge is a poor predictor of sexually transmitted infections and genital tract inflammation in highrisk women in South Africa. J Infect Dis 2012, 206:6-14.

18. Abbai NS, Wand H, Ramjee G: Sexually transmitted infections in women participating in a biomedical intervention trial in Durban: prevalence, 
coinfections, and risk factors. J Sex Transm Dis 2013, Article ID 358402:6. doi:10.1155/2013/358402.

19. Feldblum PJ, Lie CC, Weaver MA, Van Damme L, Halpern V, Adeiga A, Bakare R, Schwartz J, Becker M, Solomon S: Baseline factors associated with incident HIV and STI in four microbicide trials. Sex Transm Dis 2010, 37(10):594-601.

20. Marrazzo JM, Ramjee G, Nair G, Palanee T, Mkhize B, Nakabiito C, Taljaard M, Piper J, Gomez K, Chirenje M: Pre-exposure prophylaxis for HIV in Women: daily oral tenofovir, oral tenofovir/emtricitabine, or vaginal tenofovir gel in the VOICE Study (MTN 003). Atlanta: 20th Conference on Retroviruses and Opportunistic Infections; 2013. Abstract 26LB.

21. Gertig DM, Kapiga SH, Shao JF, David J, Hunter DJ: Risk factors for sexually transmitted diseases among women attending family planning clinics in Dar-es-Salaam, Tanzania. Genitourin Med 1997, 73:39-43.

22. Feldblum PJ, Kuyoh M, Omari M, Ryan KA, Bwayo JJ, Welsh M: Baseline STD prevalence in a community intervention trial of the female condom in Kenya. Sex Transm Inf 2000, 76:454-456.

23. de Lima SV, de Torres S, Fa'bia Gazzaneo T, Cavalcante FBT, Silva ZP, Vale'ria Hora V, Thomas Diedrich T, de Carvalho Silva P, Gomes de Melo P, Dacal ARC1, de Carvalho EMF, Feldmeier H: Sexually transmitted infections in a female population in rural north-east Brazil: prevalence, morbidity and risk factors. Trop Med Int Health 2003, 8(7):595-603.

doi:10.1186/1742-6405-11-31

Cite this article as: Naidoo et al:: High prevalence and incidence of sexually transmitted infections among women living in Kwazulu-Natal, South Africa. AIDS Research and Therapy 2014 11:31.

\section{Submit your next manuscript to BioMed Central and take full advantage of:}

- Convenient online submission

- Thorough peer review

- No space constraints or color figure charges

- Immediate publication on acceptance

- Inclusion in PubMed, CAS, Scopus and Google Scholar

- Research which is freely available for redistribution 